\title{
Transport and retention of aged anthropogenic iodine in a boreal peat bog
}

\author{
S. Maillant ${ }^{1,3}$, M.I. Sheppard ${ }^{2}$, G. Echevarria ${ }^{1}$, S. Denys ${ }^{1,3, *}$ \\ and $\mathrm{E}$. Leclerc Cessac ${ }^{3}$ \\ ${ }^{1}$ Laboratoire Sols et Environnement, UMR 1120 INPL-INRA, \\ 54500 Vandoeuvre-lès-Nancy, France \\ ${ }^{2}$ ECOMatters, PO Box 430, Pinawa, Manitoba, Canada \\ ${ }^{3}$ Andra, Direction Scientifique, Service Transferts,1-7 rue Jean Monnet, \\ 92298 Châtenay-Malabry Cedex, France \\ *Present address: INERIS, Parc Technologique ALATA, BP. 2, \\ 60550 Verneuil-en-Halatte, France
}

\begin{abstract}
Iodine-129 is a radionuclide of major concern in the international safety assessments for deep geological storage and disposal of nuclear waste because it migrates quickly through the geosphere to the biosphere and then from the soil to humans through the food-chain. However, in organic soils the ${ }^{129}$ I may be immobilized over a long time period, and so these soils represent a potential accumulation point in the biosphere. Effects of long residence times of iodine in soils are scarce. The present paper gives some insight on the aging of stable iodine under natural conditions. Stable iodine was introduced as KI in 1987 at the base of a sphagnum bog to simulate arrival of iodine via a groundwater discharge from the geosphere. Fifteen years later, the groundwater, the soil and the vegetation have been sampled and analysed for iodine. The results we present give insight on the mobility of "aged" iodine, the retention properties of the peat, and provide iodine transfer factors for native boreal plant species. This study demonstrates bogs present good sinks for iodine and limit the transfer of iodine to some of the "wildlife" food-chains.
\end{abstract}

\section{INTRODUCTION}

Iodine-129 is a radionuclide of major concern in the safety assessments of deep or near-surface geological disposal of nuclear waste [1, 2]. Since iodine is generally present in environments as an anion (either iodide or iodate), it is soluble in groundwaters and migrates relatively quickly through rock and overburden to low-lying landscape positions. In the terrestrial environment, aging effects on the mobility and bioavailability of iodine in soils has an important influence but may have more effect on organic rather than mineral soils [3]. However, most of the experiments conducted under controlled conditions consider a "recent" contamination and are focused on agronomic settings and mineral soils.

The fate of stable iodine, after a simulated localized input, was monitored in a peat bog under natural conditions [4]. Stable iodine was introduced as KI in 1987 at the base (2 m) of a small (0.6 ha) natural sphagnum bog to simulate deep groundwater rising from a geological disposal vault to the surface environment. The bog is currently vegetated by birch, alder, willow and other shrubby species such as Labrador tea, leatherleaf, sedge and Sphagnum. In 1987 through 1988, piezometer readings and samples revealed the spread of iodine outwards from the basal spike and also recorded the rise of iodine towards the bog surface [4]. "Peat solid/pore water" concentrations ratios or soil distribution coefficients $\left(\mathrm{K}_{\mathrm{d}} \mathrm{s}\right)$ were calculated for a number of positions and over a considerable range of pore 
water iodine concentrations within the bog to better understand the mobility of iodine. Some speciation work was also completed showing that iodine was present as I and not associated with soluble humic materials shortly (391 days) after its introduction [4]. The present results have been obtained in this same bog, 15 years after the introduction of iodine.

This work focuses on several aspects: 1) the mobility of the "aged" I in peat, 2) the retention properties of iodine under natural conditions with time, 3) it digs deeper into the phenomena of the localization of iodine in the ultra-structure of the peat, through the use of transmission electronic microscopy (TEM), and 4) iodine transfer factors for native boreal plant species. Points 1, 2, and 4 contribute to the modeling of the behaviour of iodine in the environment from a human and animal dose assessment perspective. Point 3 increases our knowledge of the mechanisms involved in the retention of iodine in organic soils and in the organic matter fraction of agronomic soils.

\section{METHODS}

Details on the localization and the description of the site can be found in Sheppard et al. [4].

Physico-chemical analyses of the peat were carried on aliquots/sub-samples of two peat samples (table 1) corresponding to a "0-30 cm" and a "30-50 cm" peat layer: $\mathrm{pH}$ (NF ISO 10390), organic carbon (NF ISO 10694 and NF ISO 13878), texture (adapted from NF X 31-107), CEC (NF X 31-130) and exchangeable cations (NF X 31-108), Fe, Al and Si "free" extracted according to the Mehra-Jackson method [5, 6].

Table 1. Physico-chemical characteristics of the peat.

\begin{tabular}{|cc|c|ccccc|ccccc|}
\hline \multirow{2}{*}{$\begin{array}{c}\text { Depth } \\
\text { (cm) }\end{array}$} & $\begin{array}{c}\text { Distance to } \\
\text { input tube } \\
\text { (cm) }\end{array}$ & pH & \multicolumn{6}{|c|}{ Texture (\%) } & \multicolumn{5}{|c|}{ Organic matter } \\
\cline { 4 - 11 } & & A & LF & LG & SF & SG & $\begin{array}{c}\text { C org } \\
\text { (\%) }\end{array}$ & $\begin{array}{c}\text { OM } \\
\text { (\%) }\end{array}$ & $\begin{array}{c}\text { N } \\
(\%)\end{array}$ & C/N \\
\hline $0-30$ & 75 & 4,9 & 44,4 & 38,7 & 13,5 & 0,9 & 2,5 & 41,1 & 70,8 & 2,0 & 20,5 \\
$30-50$ & 75 & 5 & 34,2 & 40 & 9,4 & 1,3 & 15 & 43,6 & 75,1 & 2,0 & 21,3 \\
\hline
\end{tabular}

The sphagnum bog is of medium acidity ( $\mathrm{pH}$ ) even though the bedrock is granitic (Canadian Shield). Table 1 shows that top and bottom layers exhibit the same pedologic characteristics ( $\mathrm{pH}, \mathrm{OM}$ content), except for a slight change in texture: the bottom layer contains more sand, as a consequence of the proximity of the altered granite.

\subsection{Spatial migration of basally positioned iodine after 15 years}

As a first step in the reinvestigation of this bog, groundwater samples were taken to determine whether further slow migration and/or changes in the retention processes had changed the distribution of iodine since 1987. Sampling in 2002, after 15 years, provides an excellent opportunity to observe the longest semi-natural experiment of mobility of iodine in near-surface groundwater, an important step in understanding time required to reach steady-state under natural wetland conditions. In August 2002, the piezometers (Fig. 1) were sampled for groundwater using the same procedure as previously [4]. Briefly, the tubes were pumped out and allowed to refill with bog groundwater and sampled using a piston pump the following day. Groundwater samples were filtered $(0.45 \mu \mathrm{m}$, cellulose nitrate), refrigerated and analysed by ICP-AES (precision for historic data: standard deviation was $7.4 \%$ at $5.0 \mathrm{mg}$ I L-1, recent detection limit (DL) for ICP was $1 \mathrm{mg} \mathrm{I} \mathrm{L-1.} \mathrm{Historic} \mathrm{DL} \mathrm{was} \mathrm{usually}<0.1 \mathrm{mg}$ L-1 and always $<0.3 \mathrm{mg} \mathrm{L}-1)$. 

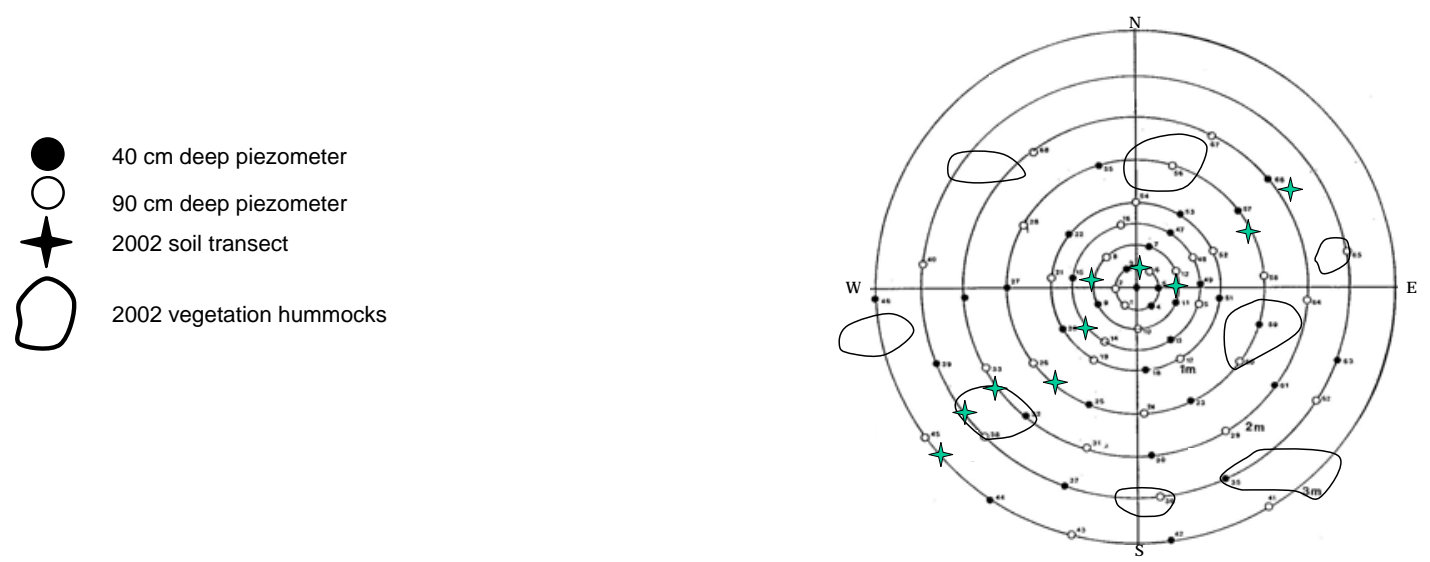

Figure 1. Diagram of the bog, showing the piezometer location for groundwater sampling (1987 through 2002) and the peat and vegetation sampling sites (2002). The centre point is the location of the access tube for the injection of the iodine.

\subsection{Peat retention $\left(K_{d}\right)$ of iodine after aging}

Peat was sampled at two depths $(0-30 \mathrm{~cm}, 30-50 \mathrm{~cm})$ along a transect in 2002. This transect extended from $25 \mathrm{~cm}$ to $300 \mathrm{~cm}$ away from the initial spiking access tube (Fig. 1). For each sample, one $25 \mathrm{~g}$ aliquot of field-moist peat was left to equilibrate for $24 \mathrm{~h}$ with $50 \mathrm{~mL}$ of water. This water had been collected from a hand-dug pit in the same bog, but away from the contaminated location, and filtered $(0.45 \mu \mathrm{m})$ before use. The soil-solution mixture was then centrifuged, the two phases were separated and analysed (the solutions by ICP and the solids by NAA, DL $<0.1 \mu \mathrm{g} \mathrm{g}^{-1}$ ). These analyses allowed the computation of $\mathrm{K}_{\mathrm{d}}$ values as

$$
\mathrm{K}_{\mathrm{d}}=[\mathrm{I}] \text { soil solid ( } \mathrm{mg} \mathrm{kg}^{-1} \text { of dry soil) / [I] peat pore water }\left(\mathrm{mg} \mathrm{L}^{-1}\right)
$$

\subsection{The localisation of iodine as influenced by the ultra-structure of peat}

Several techniques have tried to unravel the biochemical interactions of iodine and organic matter $[3,7]$ such as EDTA extractions, sterilisation, humic and fulvic acid fractionation. New techniques such as Transmission Electronic Microscopy and Energy Dispersive X-Ray spectroscopy (EDX) can give insight into the mechanisms of iodine retention such as the characteristics of the organic molecules fixing iodine, by comparing samples with high and low iodine content.

Two peat samples from the transect were chosen for this study: upper $(0-30 \mathrm{~cm})$ and lower samples $(30-50 \mathrm{~cm})$ from the same core with the highest iodine content in the solid phase. Two sub-samples were taken from the surface peat sample: recognisable (contained roots, bark, twigs) and non-recognisable material (dark mixture of humified peat). The bottom peat sample was not split into sub-samples. The two non-recognisable sub-samples were then fixed with chemical reagents before being sectioned as described in Villemin et al. [8]. Each type of ultra-structure observed with TEM was analysed for total iodine content using the EDX microprobe.

\subsection{Bioavailability of iodine to boreal plant species}

Since equilibrium should have been reached in the vascular plants, the mosses and the deep-rooted phreatophytes after 15 years, the present sampling campaign should produce excellent concentration ratios between the different plant species and their rooting media. In bogs, the vegetation builds up hummocks above the average water level. Vegetation (leaves and twigs of the year) was sampled within each of the 
eight hummocks (Fig. 1). Plants present and sampled were: alder (Alnus rugosa), willow (Salix sp), leatherleaf (Chamaedaphne calyculata), Labrador tea (Ledum groenlandicum) and sedge (Carex sp). Leaves were separated from twigs, air-dried and ground before analyses. Peat samples were taken at each of the hummocks, as close as possible to the roots of the plant sampled for vegetative material. The pore water was extracted from these soil samples by hand squeezing and filtered (0.45 $\mu \mathrm{m}$, cellulose nitrate) prior to analysis (ICP). The remaining solid phase was air-dried, and analysed (NAA).

\section{RESULTS}

The results of this work suggest the water dynamics have a direct impact on the migration of iodine in the peat bog, which then affects its transport to plants and its retention onto or within the peat material.

\subsection{Spatial migration of iodine in the bog groundwater}

Figure 2 illustrates the spatial distribution of iodine in the groundwater 15 years after the spike. Log[I] decreased with the increasing distance from the access tube at both 40 and $90 \mathrm{~cm}$ depths (Fig. 2). Iodine groundwater concentration was higher at depth than at the surface. This migration towards the bog surface can be attributed to evaporation processes or to root concentration or active uptake as suggested Sheppard and Thibault [9]. However the distribution of iodine in space was unequal due to the water dynamics in the bog. The flow of water at the base and at the surface of the bog $(90 \mathrm{~cm} \mathrm{depth})$ seemed to be carrying the iodine to multiple positions outward from the spike concentrating mostly to the west (result not shown). There may be a preferential pathway in this direction. At the bog surface, the highest iodine concentration was noted closest to the injection location.

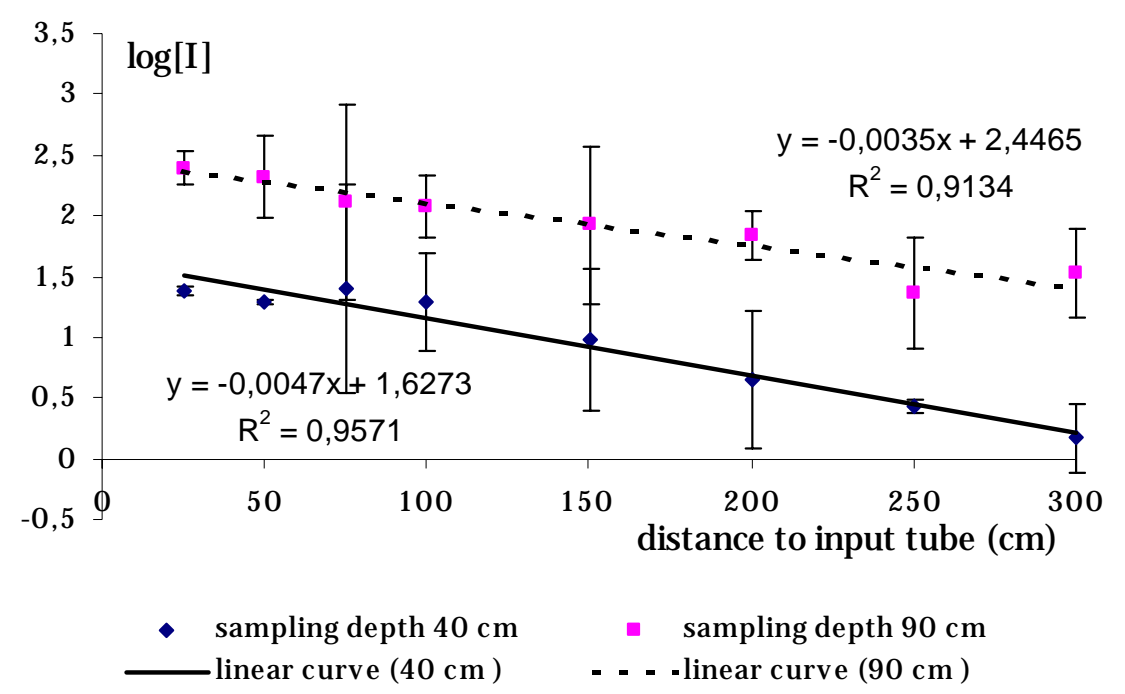

Figure 2. Distribution of I (as $\log [\mathrm{I}])$ in the groundwater in 2002 in the piezometers as a function of the distance from the access tube in cm (values are arithmetic averages of log[I] with arithmetic standard deviation).

\subsection{Retention of iodine on the peat solids after ageing}

The geometric mean (GM) of all the $K_{d}$ values computed in 2002 was: $13.8 \mathrm{~L} \mathrm{~kg}^{-1}$. The GM K $\mathrm{K}_{\mathrm{d}}$ for the surface samples $(0-30 \mathrm{~cm})$ was $37.6 \mathrm{~L} \mathrm{~kg}^{-1}$ and the $\mathrm{K}_{\mathrm{d}}$ at depth $(30-50 \mathrm{~cm})$ was $5.1 \mathrm{~L} \mathrm{~kg}^{-1}$. This difference between surface and deep samples was statistically significant. It showed also that iodine was more 
retained on the peat at the surface (oxidized conditions) than in the deep layers (saturated with water) in the peat material which is in agreement with Sheppard and Thibault [9]. It has been shown for several types of material (lake sediments, peat, soils) that iodine was less associated to the solid phase under anoxic conditions than under aerobic conditions [10,11]. In 2002, $K_{d}$ was decreasing as the distance increases (Fig. 3).

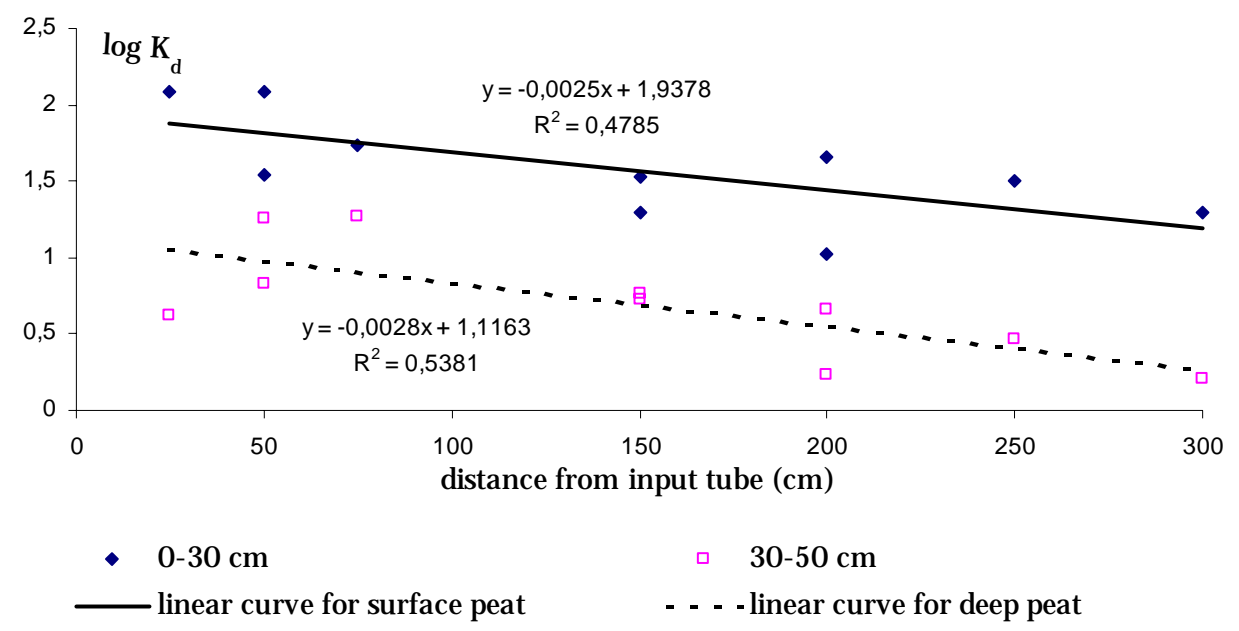

Figure 3. Changes in $K_{d}$ with depth and distance to the access tube (individual (log $K_{d}$ ) values).

\subsection{Microscopic analyses (TEM and EDX) of the peat ultra-structure}

Stained thin sections from the two layers $(0-30$ and $30-50 \mathrm{~cm})$ of peat observed with TEM showed contrasting situations. The non-recognisable sub-sample of the surface peat sample consisted of miscellaneous vegetal remains including cell components more or less dense to electrons. Some components could be recognised, such as the more or less humified cell walls, polyphenolic substances and micro-organisms. The bottom non-recognisable sub-sample was similar to the surface one, except that microbes were much less numerous and active. This microbial inactivity could be due to the high iodine content, which can be toxic to anaerobes [12] or to the saturating conditions that would kill aerobic microorganisms [13].

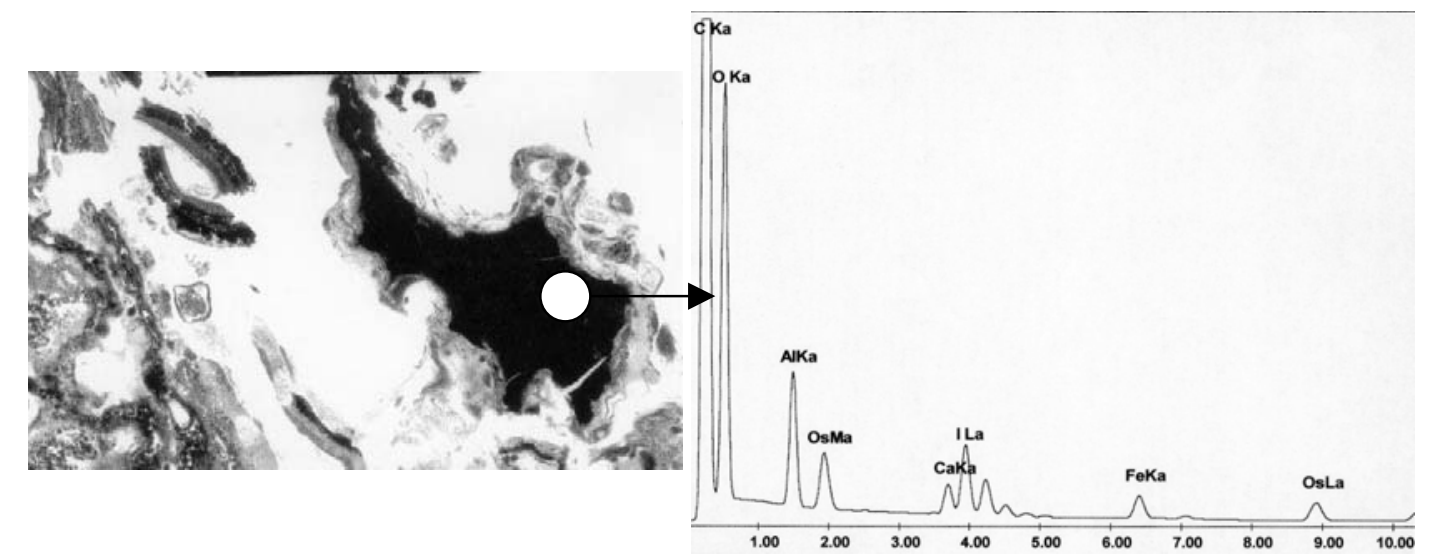

Figures 4a and $4 \mathbf{b}$. TEM microphotograph of the non-recognisable fraction of the surface sample and the corresponding EDX spectra of polyphenolic substances from this sample. The L-edge of Iodine peaks at 3,939 keV. 
Analyses for I were performed with EDX on all the ultra-structures observed with TEM: dark (high diffusive contrast) and pale (light diffusive contrast) structures, plant cell walls and intersections, clay, living and dead fungi, bacteria. The analysis revealed the presence of: $\mathrm{O}, \mathrm{Al}, \mathrm{Si}$, Os, Cl, Ca, I, Fe. Iodine was found only in the polyphenolic structures of the surface non recognisable samples (Fig. 9a and 9b) which is consistent with the high affinity of iodine for phenolic groups[7, 14]. These same morphological structures present in the bottom sample did not show any iodine content. This is in agreement with the low $\mathrm{K}_{\mathrm{d}}$ values obtained in the bottom samples. Because at least two parameters differed in the upper and the bottom layer (redox conditions and microbial activity) it was not sure whether the association of iodine with polyphenolic substances was due to chemical or microbial reactions. Both pathways have been demonstrated by several authors [10,15].

\subsection{Boreal plant iodine uptake and plant CRs}

The sedges had the highest concentrations of I, with higher concentrations in leaves than in roots among all the vegetation sampled, including shrubby species (Table 2).

Table 2. Iodine content of the vegetation of the bog.

\begin{tabular}{|l|l|c|c|c|c|}
\cline { 3 - 4 } \multicolumn{2}{c|}{} & \multicolumn{2}{c|}{$\begin{array}{c}\text { [I] in plant material } \\
\text { (mg/L) }\end{array}$} & $\begin{array}{c}\text { [I] plant/[I] } \\
\text { porewater }\end{array}$ & $\begin{array}{c}\text { [I] plant/[I] } \\
\text { total soil } \\
\text { (=CR) }\end{array}$ \\
\hline specie & plant part & GM & Geom stddev & & 0,15 \\
alder & leaf & 3,04 & 2,52 & 5,23 & 0,03 \\
leatherleaf & stem and petiole & 0,87 & 1,95 & 1,43 & 0,06 \\
leatherleaf & leaf & 1,21 & 2,68 & 2,24 & 0,04 \\
sedge & stem and petiole & 1,98 & 1,58 & 2,65 & 6,18 \\
sedge & leaf & 124,91 & 2,10 & 283,83 & 2,81 \\
tea & roots & 71,11 & 1,60 & 199,00 & 0,09 \\
tea & leaf & 1,70 & 2,69 & 2,35 & 0,06 \\
willow & stem and petiole & 2,22 & 2,10 & 1,30 & 0,13 \\
willow & leaf & 3,76 & 2,69 & 6,39 & 0,04 \\
\hline
\end{tabular}

The iodine content of the shrubs was highly variable and did not seem linked to the soil I content (neither pore water nor solid phase, results not shown). The peat sampled may not be representative of the volume explored by the roots. Plant uptake was expressed as a concentration ratio, CR, computed as the plant concentration on a dry weight basis divided by the root-zone soil concentration also on a dry weight basis. The GM of all CRs was 0,1 with a GSD of 6,8. These CRs fit in the higher part of the CR range noted for crops in the literature: from 0.0002 to $4[15,16]$. Soil $K_{d}$ values of the hummock peat were high: GM is $288 \mathrm{~L} \mathrm{~kg}^{-1}$, so it confirmed that I accumulated in the upper layers of the peat.

\section{CONCLUSION}

The present study has shown that iodine is still present in the bog groundwater and remained mobile, 15 years after the contamination in the deepest part of the bog. It was also shown that iodine tended to accumulate in the upper layers of the bog and was retained by the peat, probably through evaporation processes that favour upward migration of water, and through microbial activity that favours the incorporation of iodine into organic compounds. MET associated with EDX did show that iodine was contained in the polyphenolic structures of humified plant tissues. Therefore, organic bogs are both sinks and sources regarding iodine contamination, because iodine would be retained on the solid phase at the surface, but would also be available for plants and transport. The plants of the bog differ in their ability to take up iodine (CR values: from 0,04 to 6,2) which in turn can be interpreted in terms of food-chain accumulation. More details are needed to understand under what conditions the plants take up iodine from peat and whether vegetables grown in peat, such as specialty crops, would take up iodine. 


\section{Acknowledgments}

We acknowledge the financial assistance of Andra, Ontario Power Generation (OPG) for funding this study. We also wish to thank Barb Sanipelli and Anita Drabyk from ECOMatters, Inc. for both field and lab assistance and Steve Sheppard for critically reviewing the draft manuscript.

\section{References}

[1] SKB., Technical Report 99-06, SR 97 - Main report. (Swedish Nuclear Fuel and Waste Management Co (SKB), Sweden, 1999).

[2] Vieno T. and Nordman H., TILA-99, Safety assessment of spent fuel disposal in Hästholmen, Kivetty, Oililuoto and Romuvaara. (Posiva Oy report, 99-07. Helsinki, Finland, 1999).

[3] Sheppard M.I. and Thibault D.H., Applied geochem. 7 (1992) 265-272.

[4] Sheppard, M.I., Thibault D.H. and Smith P.A., Applied geochem. 4 (1989) 423-432.

[5] AFNOR, Evaluation de la qualité des sols, (Association Française de Normalisation, Paris, 2004).

[6] Rouiller J., Souchier, B., Bruckert S., Feller C., Toutain F. and Vedy J.C., In: Pedologie.Vol2: Constituants et propriétés du sol. Edited by M. Bonneau and B. Souchier (Masson, Paris, 1994). pp 619-652.

[7] Whitehead D.C., Environ. intern. 10 (1984) 321-339.

[8] Villemin G., Mansot J.L., Watteau F., Ghanbaja J. and Toutain F., C.R. Acad. Sci. T.321 (1995) 861-868.

[9] Sheppard M.I. and Thibault D.H., J.Environ.Quality. 17 (1988) 644-653

[10] Bird G.A. and Schwartz W., J. Environ.Radioactivity. 35 (1996) 261-279.

[11] Sheppard S.C. and Motycka M., J.Environ.Radioactivity. 37 (1997) 339-353.

[12] Sheppard M.I. and Hawkins J.L., J.Environ.Radioactivity. 29 (1995) 91-109.

[13] Brake M., Hoper H. and Joergensen R.G., Soil Biol. Biochem. 31 (1999) 1489-1497.

[14] Warner J.A., Casey W.H. and Dahlgren R.A., Environ.Sci.Technol. 34 (2000) 3180-3185.

[15] Muramatsu Y., Yoshida S., Ban-nai T. and Amachi S., Radioprotection-Colloques. 37 (2002) 479-484.

[16] Sheppard S. and Evenden W., J.Environ.Radioactivity. 7 (1988) 221-247. 